\title{
AOR
}

Selected Papers of \#AolR2018:

The $19^{\text {th }}$ Annual Conference of the

Association of Internet Researchers

Montréal, Canada / 10-13 October 2018

\section{PUBLIC SPEECH: LISTENING TO WOMEN IN THE VIDEOGAME INDUSTRY}

\author{
Suzanne de Castell \\ University of Ontario Institute of Technology \\ Karen Skardzius \\ York University

\section{Background}

"I feel like we should be asking ourselves less what should game studios be doing to encourage women into the industry, and [more about] what could change about our culture to make women feel welcome and able to speak freely".

Since the 1990s, conversations about the dearth of women working in the video game industry have centered on three topics: 1) ways to draw more women into the field, 2) the experiences of women working in the industry, and 3) the experiences of those who once worked in the industry but left (Cassell \& Jenkins, 1998; Hepler, 2017; Kafai, Heeter, Denner \& Sun, 2008). While there has been considerable research on the conditions and occupational identities of video game developers, less scholarly attention has been devoted to women in games work, the barriers/obstacles and challenges/opportunities they face, or how they talk about their experiences. Our study concentrates on what women employed by the industry have to say about the subject and how they are saying it. What we have found is a considerable gap between how women's working conditions are reported in both research and popular press, and how women in the games industry speak about them "in public".

Methodologically, this discourse-analytic study is guided by Taylor's (1998) five features of feminist methodology: "a focus on gender and gender inequality, a spotlight on the everyday experiences of women, reflexivity as a source of insight, an emphasis on participatory methods, and a policy or action component" (360). Our research seeks to enhance women's resources rather than exploit them. We found that the women whose viewpoints we are interested in have persistently and emphatically conveyed their frustration about having to speak so often about and for their gender. Game developer Brenda Romero describes the problem as the "female tax": the extra time and effort women who make games must expend in discussing gender on top of their work, 
whenever they engage in any type of public speaking. Taking their public voices seriously, listening to what women in games have already said on this issue, led us to use existing interviews and discussions of gender and/in the games industry from various media as primary data. In other words, instead of surveying and interviewing prospective informants, this study looked to see who among the group of women who work in the games industry has already invested her time and energy to tell a public story, whether that is in a blog posting, a book chapter, a televised talk, a radio interview, or other public media, and built the foundations of the study by focusing on that sub-group. Following our analysis of this data, we began efforts to contact the women included in this study for the purpose of "member checking" - both to ensure the accuracy of our representations and to offer an alternative space for discussion outside the constraints of public speech.

The study includes analysis based on public accounts from 190 women working predominantly in North America. Using the list of 190 names, we began looking for anything these women had said 'in public' about their work. We completed a series of internet searches, first using each woman's name, then their name and "video games", and finally their name and "diversity". Using the texts as a kind of "virtual interview" material, we sought to answer some basic questions: where are they currently employed? How long have they worked in the industry? What role/job(s) do they fill? What education/experience do they have? What drew them to the industry? Do they talk about gender/race/sexuality, and if so how? Have they had to leave a job, and if so, why? Do they describe positive experiences in industry? Do they describe negative experiences in industry? What do they say about diversity? Excerpting both factual information and narrative passages from these texts that responded to our initial set of queries, we compiled a spreadsheet of our research 'data' and began an initial coding pass. We organized the data into three broad categories, conceptualized as points at either end of an 'affectivity' continuum, from affirmative and 'positive' accounts through 'neutral', 'how things are' descriptions, to negative and 'critical' accounts.

Next, we selectively transcribed women's public statements and sorted data into these categories on the basis of uses of 'keywords': for critical accounts, we used 'bias', 'harassment', and related terms; for positive accounts, "love", "passion" and cognates. We added to the "critical" set, "Barriers/Obstacles", and to the "positive" set "Challenges/Opportunities". Looking at how women talked about their work in games, we found positive accounts far more frequently voiced, and voiced by more women, than critical ones. Where criticism was expressed, it was most often done so in ways that 'de-fused' the incident described; for instance, mentions of "bias" were most often further characterized as "unconscious" or "unintentional", a variety of what Clair (2009) calls "trivialization".

Rosalind Gill (2014) suggests that it is through discourses and practices of power that "gender inequality has become if not unspeakable, then, extremely difficult to voice" (511). So, when searching for patterns in those texts regarding who speaks, and in what ways, about their experiences working in the games industry, it is also important to ask who does not speak, what is not said, and why. This allows us to consider women's discursive decisions as strategic ones about what and how to speak publicly of their workplace experiences. What informs and constrains those decisions? In seeking to 
learn about workplace policies, wages, job descriptions or working conditions, and the varied ways these may be experienced by women involved, the further question is whether and how women speak publicly about them.

Analyzing uses of the words 'love' and 'passion' as rhetorical devices that express "positivity", for example, the question we pose is about what kind of work these invocations of love and passion do in women's accounts of their experiences and conditions. Most frequently invoked is a love of video games, which, while that might well be true, may also be functioning as a rhetorical means of claiming authority and rationalizing one's rightful presence in video game-making spaces. That makes sense if indeed many women find it difficult to feel they have a 'place' in the games industry. Not only do women frequently point out that they currently love video games, but they point out that video games have been with them far longer than their job(s) making them. While making video games because you love them makes for a logical career choice, there is also a clearly critical undertone to many of the ways this love and/or passion is talked about. Game developer Anna Megill directly addresses the tension between pursuing a career in making games because you love them, and the costs of doing so: "Yes, there's harassment and ugliness, but the industry is also full of creative, brilliant, passionate people. We all share a love of games. Don't let bullies stop you from being part of that" (Fissenden, 2014).

This paper demonstrates how identifying the rhetorical constraints that public speech imposes upon what can be said about "women in games" aids us in understanding what might remain unspoken, and why.

\section{References}

Cassell, J., \& Jenkins, H. (1998). From Barbie ${ }^{\circledR}$ to Mortal Kombat: Gender and Computer Games. Cambridge, Mass: The MIT Press.

Clair, Robin P. (1993). The Use of Framing Devices to Sequester Organizational Narratives: Hegemony and Harassment. Communication Monographs, Vol. 60,113-136.

Fissenden, Emma. (November 26, 2014). Game Changer: Developer Anna Megill Talks Representation, Riven, And Ragequitting. Retrieved February 28, 2018, from https://www.themarysue.com/game-changer-anna-megill/.

Gill, R. (2014). Unspeakable Inequalities: Post Feminism, Entrepreneurial Subjectivity, and the Repudiation of Sexism among Cultural Workers. Social Politics, 21(4), 509-528. https://doi.org/10.1093/sp/jxu016

Hepler, J. B. (2017). Women in Game Development: Breaking the Glass Level-Cap. Boca Raton, FL: CRC Press. 
Kafai, Y. B., C. Heeter, J. Denner \& J. Y. Sun. (2008). Beyond Barbie and Mortal Kombat: New Perspectives on Gender and Gaming. Cambridge, Mass: MIT Press.

Romero, Brenda. (2016). TEDx Talks. The Female Tax. TEDxSantaCruz. Retrieved from https://www.youtube.com/watch?v=W1FCY- LOx4.

Taylor, V. (1998). Feminist Methodology in Social Movements Research. Qualitative Sociology, 21(4), 357-379. 